\title{
Computer-Aided Planning in Construction Evaluations of Alternatives in Construction Planning
}

\author{
Naruo Kano \\ Department of Architecture, Waseda University, Professor \\ Email:kano@mn.waseda.ac.jp
}

\begin{abstract}
In this paper, the author developed five evaluation models for selecting among alternate construction methods based on past construction records and studied the reliability of the models by applying each to excavation retaining wall construction. The author also proposed the Majority Evaluation Method to improve the reliability of these evaluation models and employed computers to select an appropriate alternate construction method.
\end{abstract}

Keywords: Construction Planning, Computer-Aided Planning, Construction Methods, Excavation Retaining Wall, Majority Evaluation Methods

\section{Introduction}

Many areas of construction planning require the knowledgeable judgment of experienced engineers, particularly in the initial stages of planning when sufficient data needed to make a decision is less likely to be available. During these stages, it is common practice to rely on the decisions of experienced engineers.

When using a computer to select one of several construction methods based on ambiguous data, we would develop a method for assessing construction plans retrogressively by analyzing data on past construction projects. While there are many evaluation models ${ }^{1)}{ }^{2)}$ and a few applications ${ }^{3)}{ }^{4)}$ have been implemented, such a method has yet to be employed in the wide range of applications in construction planning.

In this paper, the author developed five evaluation models for selecting among alternate construction methods based on past construction projects and studied the reliability of the models by applying each to excavation retaining wall construction. The author also proposed the Majority Evaluation Method to improve the reliability of these evaluation models and employed computers to select an appropriate alternate construction method.

\section{Needs Computer-Aided Planning with Company's Experience}

\subsection{Engineer's Experience in Construction Planning}

Even without receiving detailed information or performing involved calculations, experienced engineers can generally select an appropriate construction method for specific problems with a degree of reliability. Their ability to do this has been widely recognized from past performances in construction planning. Engineers that have learned construction projects through experience can 
unconsciously form analogous connections between past construction projects and a current situation based on the knowledge they accumulated.

\subsection{Limitations of an Engineer's Experience}

The scope of an engineer's experience is primarily defined by the construction projects he or she has directed. Since an engineer does not generally work on a large number of projects in a year, one engineer must work for a considerably long time in order to accumulate enough experience to make informed decisions. Hence, even if a company has a long track record of construction achievements, the company will eventually lose its ability to apply that experience as the senior engineers with the most knowledge eventually quit or retire from the company. The company must then wait for other engineers to accumulate enough experience in order to regain this knowledge.

Consequently, engineers without sufficient experience are often responsible for making planning decisions, resulting in companies making the same poor planning decisions time and again.

\section{Models for Selection}

\subsection{Models for Selecting Construction Methods}

When forming plans during the bidding stage and the initial stages of construction planning, it is necessary to develop a rough course of action based on an outline to determine the appropriate construction methods to employ. During these stages it is more important to develop a general idea of possible construction methods based on sketchy construction data than to compare the detailed cost factors of each construction method.

In this paper, the author used the following five models to determine an appropriate construction method.

1) Discriminant Analysis Model

2) Preference Analysis Model

3) Neural Network Model

4) Case-Based Model

5) Rule-Based Model

\subsection{Discriminant Analysis Model}

This model assumes that the attributes of construction projects can be represented by parameters Xi (X1, X2, $\mathrm{X} 3, \ldots, \mathrm{Xn})$ that will reveal the construction method Gi employed in each project. Discriminant analysis is employed to find a discriminant function for classifying each construction project according to each group of methods employed.

\subsection{Preference Analysis Model}

Preference analysis employs a hypothetical linear function for evaluating the selections and finds a coefficient for this function such that the value of the function for an employed method is larger than that for other methods. Equation (1) below was defined for all construction methods $\mathrm{k}$ when employing $\mathrm{a}$ method $\mathrm{j}$ in a construction project $\mathrm{i}$, where $\mathrm{k} \neq \mathrm{j}$.

$$
\mathrm{Sij}>\mathrm{Sik}
$$

Here, the preference function $\mathrm{Sij}$ is expressed as a linear function. Solutions of half-space problems, such as the least-squares or relaxation procedures, are used to find a linear function to express the preference based on past construction projects.

\subsection{Neural Network Model}

A neural network is a computer network model based on a nervous system in which neurons connected in a series are stimulated and in turn stimulate other neurons in the series. The attributes $\mathrm{Xi}$ are the stimuli applied to the neurons, which in turn stimulate other neurons in the series. The result is the construction of 
a neural network, in which specific neurons display numbers representing a construction method to be employed in the construction project.

\subsection{Case-Based Model}

In this method, past construction records is referenced to find parameters that indicate attributes of the construction project. After normalizing the parameters, a case-based model is constructed to express the attributes of construction projects. Attributes of a target construction project are matched with those of projects stored in the case-based model. The construction method for the project that most closely resembles the target project is assumed to be employed. The squared Euclidian distance is used to evaluate similarity.

\subsection{Rule-Based Model}

Criteria that engineers use to select a method are modeled as if-then rules. Usually, engineers themselves do not understand the process they use to determine a method based on their experience. In this study, the author interviewed an expert of construction planning. The thought process he used to reach a solution was recorded and converted into if-then rules.

\section{Evaluation for Excavation Retaining Wall Construction Methods}

\subsection{Excavation Retaining Wall Construction}

When excavating an area for constructing underground floors, retaining walls are set in place to prevent soil around the excavated area from collapsing inward. There are three principal methods for constructing these retaining walls.

(1) H-Pile Wall (Soldier Piles)

In the H-Pile Wall method, Steel H-Piles are set into the ground from above. As the area is excavated, timber is attached crosswise to the H-Pile to prevent soil from collapsing inward. This method is not optimal when groundwater is present, because the water tends to seep through gaps in the retaining wall (see Figure 1).

(2) Steel Sheet Pile Wall

A Steel Sheet Pile Wall is installed by interlocking the pile walls together. Because the pile walls are linked together, groundwater cannot seep through the wall into the excavated side. This method is not suitable for deep excavation since the wall has little rigidity to withstand pressure from the soil (see Figure 2).

\section{(3) Cast-in-Place Wall}

The wall section area is excavated using an earth drill positioned above ground on the edge of the excavation area. Soil is mixed with a cement paste, replacing the soil with soil cement to create a cast-inplace retaining wall (see Figure 3.a). It is also possible to build a reinforced concrete wall under the ground. This is done by excavating the retaining wall area with an excavator while the hole is kept filled with bentonite slurry, and installing reinforcing bars in the wall area and placing concrete (see Figure 3.b). Both of these types of Cast-in-Place Walls are suitable for groundwater and deep excavation. However, they are expensive to construct. 


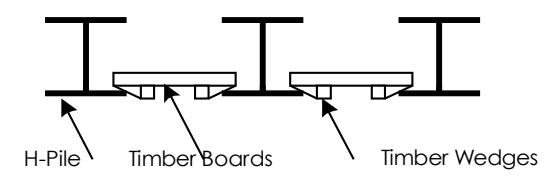

Figure.1 $\mathrm{H}$-Pile Wall

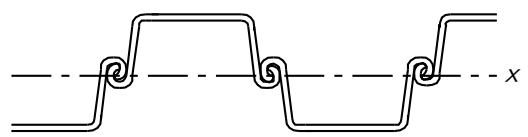

Figure.2 Steel Sheet Pile Wall

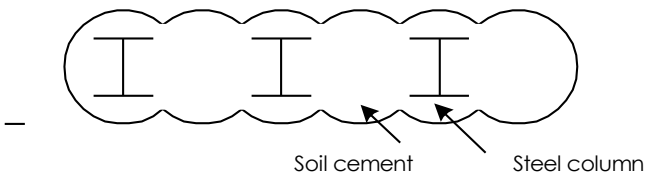

a. Soil Cement Column Wall

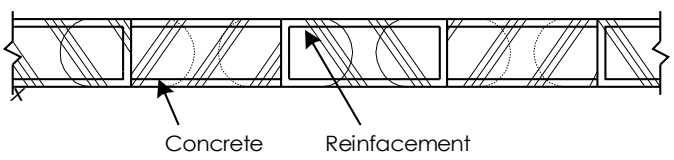

b. Reinforced Concrete Wall

Figure.3 Cast-in-Place Wall

\subsection{Collecting Data on Previous Projects}

In order to determine the precision of deductions using the five evaluation models described in the influence on the selection of a method for excavation retaining wall construction, the author defined nine variables to represent these factors in the following lists..

a. Excavation depth (m)

b. Excavation area $\left(\mathrm{m}^{2}\right)$

c. Depth of groundwater level from excavation bottom (m)

d. Thickness of gravel soil, fine-sand soil, rock soil, and surface soil layers between the groundwater level and excavation bottom $(\mathrm{m})$

e. Thickness of fine-grained soil and organic soil layers between the groundwater level and excavation bottom (m)

f. Average N-value (SPT blow count) for soil between the ground surface and the excavation bottom

g. Ratio of fine-sand soil between the ground surface and excavation bottom

h. Ratio of fine-grained soil and organic soil between the ground surface and excavation bottom

i. Thickness of firm soil layer ( $\mathrm{N}$-value of 50 or greater) between the ground surface and the excavation bottom (m)

Table.1 Mean Values of Attributes of Constrction Projects

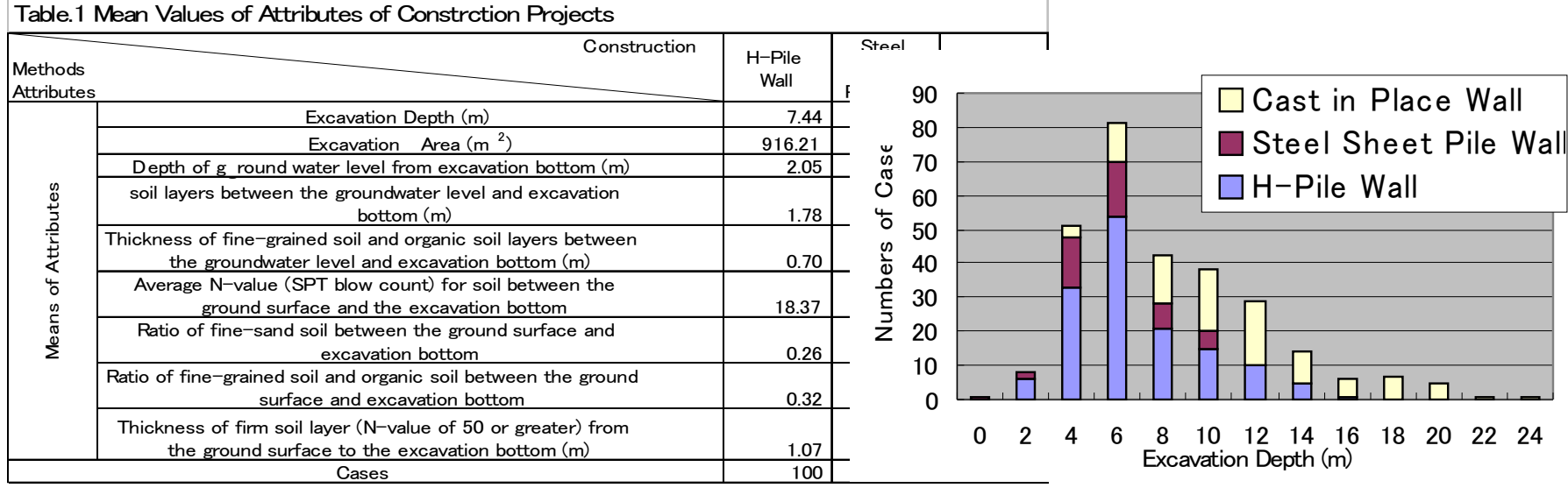

previous section, the author collected and analyzed data on underground construction projects performed throughout Japan. All of the construction projects were started between 1965 and 1986 and had excavation depths of 2-25 meters and excavation areas of $50-15,000 \mathrm{~m}^{2}$. All projects using the Open Cut method were excluded.

After analyzing factors that would have
Figure.4 Excavation Retaining Walls

By studying the records for previous construction projects, as described above, the author obtained valid data for 324 cases. Table 1 shows the mean values of attributes of construction projects for each of the construction methods. Figure 4 shows the number of construction projects according to excavation depth 
and excavation retaining wall method.

To develop evaluation models, cases for each construction method was randomly divided into two groups with one group having approximately twice as much data as the other. The larger of the groups were used for analyzing models (analysis data) and the smaller was used for verifying the models (verification data).

\subsection{Construction Method Evaluation Models}

\subsubsection{Discriminant Analysis Model}

Using the nine descriptive variables described above, the author attempted to find a linear discriminant function for distinguishing between the three construction methods, H-Pile Wall, Steel Sheet Pile Wall, and Cast-in-Place Wall. The following discriminant functions (2) and (3) were obtained after performing discriminant analysis on the analysis data.

$$
\begin{aligned}
X= & 1.65 \times 10^{-1} \mathrm{a}+8.09 \times 10^{-5} \mathrm{~b}+4.97 \times 10^{-2} \mathrm{c} \\
& +2.59 \times 10^{-1} \mathrm{~d}-9.54 \times 10^{-2} \mathrm{e}-2.34 \times 10^{-2} \mathrm{f} \\
& -1.10 \times 10^{-1} \mathrm{~g}-5.53 \times 10^{-1} \mathrm{~h}-2.29 \times 10^{-1} \mathrm{i}-1.95
\end{aligned}
$$

$$
\begin{aligned}
\mathrm{Y}= & 2.94 \times 10^{-1} \mathrm{a}+1.03 \times 10^{-4} \mathrm{~b}-2.56 \times 10^{-1} \mathrm{c} \\
& +5.22 \times 10^{-2} \mathrm{~d}-6.78 \times 10^{-2} \mathrm{e}+7.21 \times 10^{-2} \mathrm{f} \\
& -4.43 \times 10^{-1} \mathrm{~g}+3.28 \times 10^{-1} \mathrm{~h}-2.79 \times 10^{-1} \mathrm{i}-2.52
\end{aligned}
$$

Here, variable ' $a$ ' to ' $i$ ' are correspond to the lists of attributes of construction projects. In the analysis data, $75.0 \%$ of the methods determined matched the methods that were actually used.

Table 2 shows the results of the accuracy of selecting appropriate construction methods for specific projects using the above discriminant functions on the verification data. As shown in Table 2 , the accuracy of cases that matched is $72.2 \%$, indicating a slight drop from the accuracy in the analysis data. Although relatively high accuracy was achieved with the verification data in deducing projects employing H-Pile Walls (71.1\%) and projects employing Cast-in-Place Walls (80.0\%), the accuracy rate for deducing projects using Steel Sheet Pile Wall was only $60.0 \%$.

\subsubsection{Preference Function Model}

A preference function $\mathrm{Sij}$ was created using equation (4) below for a construction method j employed in a construction project $i$.

$$
\mathrm{Sij}=\sum A k l * V i k * M j l
$$

$$
(\mathrm{k}=1 \text { to } 9, \mathrm{l}=1 \text { to } 3)
$$

Here, $\mathrm{Akl}$ is predicator variables of preference function. Vik is the $\mathrm{k}$ th attribute of construction project $\mathrm{i} . \mathrm{Mjl}$ is the 1 th attribute of construction method $\mathrm{j}$. The attributes of construction methods represent the resistance degree for groundwater, the rigidity to withstand pressure and the index of construction cost.

Using the analysis data, the author analyzed predicator variables $\mathrm{Akl}$ for the preference function that would yield satisfactory preference results in terms of numerical value when analyzing past projects with the function. With the analysis data, the author compared the construction method determined by the function to the actual construction method and found an accuracy of $73.3 \%$. 
The results shown in Table 3 were obtained by

\begin{tabular}{|c|c|c|c|c|c|}
\hline \multirow[t]{3}{*}{ Table.2 } & \multicolumn{4}{|c|}{ Results by Discriminant Analysis Model } & \multirow[b]{3}{*}{ Total } \\
\hline & & \multicolumn{3}{|c|}{ Original Membership } & \\
\hline & on Retaining Wa & $\mathrm{H}$-Pile Wall & $\begin{array}{c}\text { Steel Sheet } \\
\text { Pile Wall }\end{array}$ & $\begin{array}{c}\text { Cast in } \\
\text { Place Wall }\end{array}$ & \\
\hline \multirow{6}{*}{$\begin{array}{l}\text { Predicted } \\
\text { Group } \\
\text { Membership }\end{array}$} & \multirow{2}{*}{ H-Pile Wall } & 32 & 1 & 0 & 33 \\
\hline & & $71.1 \%$ & $6.7 \%$ & $0.0 \%$ & $36.7 \%$ \\
\hline & \multirow{2}{*}{$\begin{array}{l}\text { Steel Sheet } \\
\text { Pile Wall }\end{array}$} & 11 & 9 & 6 & 26 \\
\hline & & $24.4 \%$ & $60.0 \%$ & $20.0 \%$ & $28.9 \%$ \\
\hline & \multirow{2}{*}{$\begin{array}{l}\text { Cast in Place } \\
\text { Wall }\end{array}$} & 2 & 5 & 24 & 31 \\
\hline & & $4.4 \%$ & $33.3 \%$ & $80.0 \%$ & $34.4 \%$ \\
\hline \multirow{2}{*}{\multicolumn{2}{|c|}{ Total }} & 45 & 15 & 30 & 90 \\
\hline & & $100.0 \%$ & $100.0 \%$ & $100.0 \%$ & $100.0 \%$ \\
\hline & & & \multicolumn{2}{|c|}{ Persentage of Accuracy: } & $72.2 \%$ \\
\hline \multirow{4}{*}{\multicolumn{2}{|c|}{ Results by $P$}} & & & & \\
\hline & & & & & \\
\hline & & \multicolumn{3}{|c|}{ Original Membership } & \\
\hline & & $\mathrm{H}$-Pile Wall & $\begin{array}{c}\text { Steel Sheet } \\
\text { Pile Wall } \\
\end{array}$ & $\begin{array}{c}\text { Cast in } \\
\text { Place Wall }\end{array}$ & Total \\
\hline \multirow{6}{*}{$\begin{array}{l}\text { Predicted } \\
\text { Group } \\
\text { Membership }\end{array}$} & \multirow{2}{*}{ H-Pile Wall } & 41 & & & 54 \\
\hline & & $91.1 \%$ & $40.0 \%$ & $23.3 \%$ & $60.0 \%$ \\
\hline & \multirow{2}{*}{$\begin{array}{l}\text { Steel Sheet } \\
\text { Pile Wall }\end{array}$} & 2 & 3 & 1 & 6 \\
\hline & & $4.4 \%$ & $20.0 \%$ & $3.3 \%$ & $6.7 \%$ \\
\hline & \multirow{2}{*}{$\begin{array}{l}\text { Cast in Place } \\
\text { Wall }\end{array}$} & 2 & 6 & 22 & 30 \\
\hline & & $4.4 \%$ & $40.0 \%$ & $73.3 \%$ & $33.3 \%$ \\
\hline \multirow{2}{*}{\multicolumn{2}{|c|}{ Total }} & 45 & 15 & 30 & 90 \\
\hline & & $100.0 \%$ & $100.0 \%$ & $100.0 \%$ & $100.0 \%$ \\
\hline & & & \multicolumn{2}{|c|}{ Persentage of Accuracy: } & $73.3 \%$ \\
\hline Table.4 & \multicolumn{4}{|c|}{ Results by Neural Network Model } & \\
\hline \multirow{2}{*}{\multicolumn{2}{|c|}{ Excavation Retaining Wa }} & \multicolumn{3}{|c|}{ Original Membership } & \\
\hline & & $\mathrm{H}$-Pile Wall & $\begin{array}{c}\text { Steel Sheet } \\
\text { Pile Wall }\end{array}$ & $\begin{array}{c}\text { Cast in } \\
\text { Place Wall }\end{array}$ & Total \\
\hline \multirow{6}{*}{$\begin{array}{l}\text { Predicted } \\
\text { Group } \\
\text { Membership }\end{array}$} & \multirow{2}{*}{ H-Pile Wall } & 34 & 2 & 0 & 36 \\
\hline & & $75.6 \%$ & $13.3 \%$ & $0.0 \%$ & $40.0 \%$ \\
\hline & \multirow{2}{*}{$\begin{array}{l}\text { Steel Sheet } \\
\text { Pile Wall } \\
\end{array}$} & 6 & 5 & 6 & 17 \\
\hline & & $13.3 \%$ & $33.3 \%$ & $20.0 \%$ & $18.9 \%$ \\
\hline & \multirow{2}{*}{$\begin{array}{l}\text { Cast in Place } \\
\text { Wall }\end{array}$} & 5 & 8 & 24 & 37 \\
\hline & & $11.1 \%$ & $53.3 \%$ & $80.0 \%$ & $41.1 \%$ \\
\hline \multirow{2}{*}{\multicolumn{2}{|c|}{ Total }} & 45 & 15 & 30 & 90 \\
\hline & & $100.0 \%$ & $100.0 \%$ & $100.0 \%$ & $100.0 \%$ \\
\hline
\end{tabular}

\begin{tabular}{|c|c|c|c|c|c|}
\hline \multirow[b]{2}{*}{ Table 5} & \\
\hline & \multicolumn{4}{|c|}{ Results by Case-Based Model } & \multirow[b]{3}{*}{ Total } \\
\hline \multirow{2}{*}{\multicolumn{2}{|c|}{ Excavation Retaining Wa }} & \multicolumn{3}{|c|}{ Original Membership } & \\
\hline & & H-Pile Wall & $\begin{array}{c}\text { Steel Sheet } \\
\text { Pile Wall }\end{array}$ & $\begin{array}{c}\text { Cast in } \\
\text { Place Wall }\end{array}$ & \\
\hline \multirow{6}{*}{$\begin{array}{l}\text { Predicted } \\
\text { Group } \\
\text { Membership }\end{array}$} & \multirow{2}{*}{ H-Pile Wall } & 34 & 3 & & 40 \\
\hline & & $75.6 \%$ & $20.0 \%$ & $10.0 \%$ & $44.4 \%$ \\
\hline & \multirow{2}{*}{\begin{tabular}{|l} 
Steel Sheet \\
Pile Wall \\
\end{tabular}} & 7 & 7 & 3 & 17 \\
\hline & & $15.6 \%$ & $46.7 \%$ & $10.0 \%$ & $18.9 \%$ \\
\hline & \multirow{2}{*}{$\begin{array}{l}\text { Cast in Place } \\
\text { Wall }\end{array}$} & 4 & 5 & 24 & 33 \\
\hline & & $8.9 \%$ & $33.3 \%$ & $80.0 \%$ & $36.7 \%$ \\
\hline \multirow{2}{*}{\multicolumn{2}{|c|}{ Total }} & 45 & 15 & 30 & 90 \\
\hline & & $100.0 \%$ & $100.0 \%$ & $100.0 \%$ & $100.0 \%$ \\
\hline
\end{tabular}

\begin{tabular}{|c|c|c|c|c|c|}
\hline Table. 6 & \multicolumn{3}{|c|}{ Results by Rule-Based Model } & & \multirow[b]{3}{*}{ Total } \\
\hline \multirow{2}{*}{\multicolumn{2}{|c|}{ Excavation Retaining Wa }} & \multicolumn{3}{|c|}{ Original Membership } & \\
\hline & & $\mathrm{H}$-Pile Wall & $\begin{array}{c}\text { Steel Sheet } \\
\text { Pile Wall }\end{array}$ & $\begin{array}{c}\text { Cast in } \\
\text { Place Wall }\end{array}$ & \\
\hline \multirow{6}{*}{$\begin{array}{l}\text { Predicted } \\
\text { Group } \\
\text { Membership }\end{array}$} & \multirow{2}{*}{ H-Pile Wall } & 36 & 2 & 3 & 41 \\
\hline & & $80.0 \%$ & $13.3 \%$ & $10.0 \%$ & $45.6 \%$ \\
\hline & \multirow{2}{*}{$\begin{array}{l}\text { Steel Sheet } \\
\text { Pile Wall } \\
\end{array}$} & 4 & 11 & 5 & 20 \\
\hline & & $8.9 \%$ & $73.3 \%$ & $16.7 \%$ & $22.2 \%$ \\
\hline & \multirow{2}{*}{$\begin{array}{l}\text { Cast in Place } \\
\text { Wall }\end{array}$} & 5 & 2 & 22 & 29 \\
\hline & & $11.1 \%$ & $13.3 \%$ & $73.3 \%$ & $32.2 \%$ \\
\hline \multirow{2}{*}{\multicolumn{2}{|c|}{ Total }} & 45 & 15 & 30 & 90 \\
\hline & & $100.0 \%$ & $100.0 \%$ & $100.0 \%$ & $100.0 \%$ \\
\hline
\end{tabular}

applying the preference function found above on the verification data. The accuracy of the preference function was $69.0 \%$ overall. The percentage of accurately deducing $\mathrm{H}$-Pile Wall was high at $75.6 \%$. Cast-in-Place walls were accurately determined at $80.0 \%$. However, the accuracy rate of determining the Steel Sheet Pile Wall was only $46.7 \%$.

\subsubsection{Neural Network Model}

The network architecture was determined by selecting a number of intermediate layers and neurons through trial and error. In the current model, we selected one intermediate layer having eight neurons. The Sigmoid Function, which is the most commonly used function in neural networks, was employed to represent the synapses.

Network training was performed 20,000 times using the analysis data. The best result for the analysis data was obtained on the $7,729^{\text {th }}$ trial.

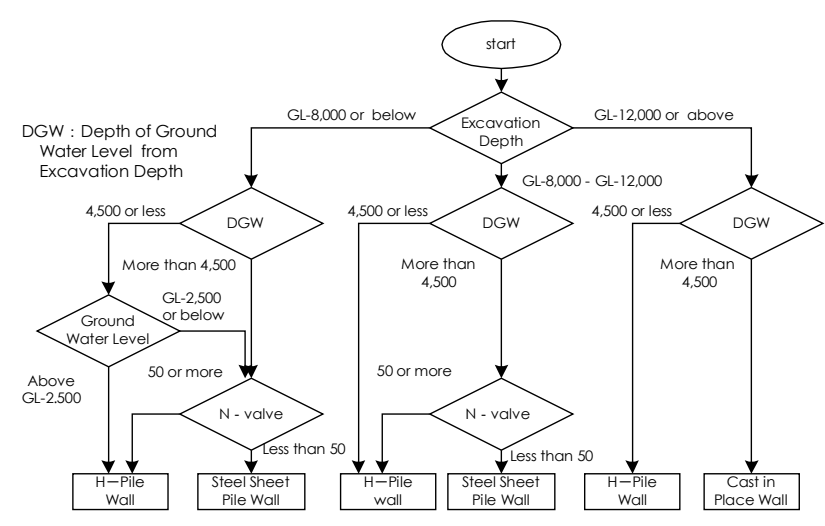

Figute.5 Flowchart of IF-THEN Rules

Therefore, the network for this trial was adopted. The accuracy in guessing the construction method for analysis data at this time was $84.0 \%$.

Table 4 shows the results of applying the neural network to the verification data. This table shows that an accuracy of $70.0 \%$ overall was obtained for the verification data. The highest accuracy of $80.0 \%$ was obtained when deducing Cast-in-Place wall. Next was the estimation of H-Pile Wall at an accuracy of $75.6 \%$. However, the percentage for accurately selecting Steel Sheet Pile Wall was only $33.3 \%$.

\subsubsection{Case-Based Model}

A database of construction cases was created using the analysis data. This database employed 194 
construction projects, where each case represented a project using nine attributes. In order to find an overall similarity between these past projects and the target construction project, each of the nine attributes has been normalized to achieve a mean value of 0.0 and a standard deviation of 1.0.

After normalizing the attributes of each target project in verification data by using the mean and standard deviation of the attribute in the database, the author extracted from the database a construction case which is most similar to the target project. The method that had been employed in the extracted construction project was assumed as the method for the target construction project.

Table 5 shows the results of deducing methods of construction projects in the verification data using the above method. The overall percentage of accuracy in our deductions was $77.0 \%$. The highest accuracy of 91.1\% was achieved for projects employing H-Pile Wall. An accuracy of $73.3 \%$ was achieved for projects employing Cast-in-Place Wall. Deductions for Steel Sheet Pile Wall were extremely low at 20.0\% accuracy.

\subsubsection{Rule-Based Model}

An interview was conducted with an engineer having more than thirty years of experience. The process in which the engineer used to determine construction methods based on experience was modeled in if-then rules. Since the engineer himself was not conscious of his/her procedure for determining methods based on experience, these rules were created through trial and error in the meetings which were conducted over four times lasting roughly two hours each.

The flowchart shown in Figure 5 was created based on the above expert rules for selecting construction methods.
Table 6 shows the accuracy when using the RuleBased Model of Figure 5 on the verification data to determine an appropriate construction method. The overall accuracy was $76.0 \%$ with an $80.0 \%$ accuracy for construction projects employing H-Pile Wall, $73.0 \%$ accuracy for construction projects employing Steel Sheet Pile Wall, and $73.3 \%$ accuracy for construction projects employing Cast-in-Place Wall. Hence, the Rule-Based Model achieved relatively high accuracy even when determining Steel Sheet Pile wall projects, which yielded comparatively low accuracy when using other deduction methods.

\section{Majority Evaluation Method}

Each of the five models introduced in Section 4 were able to achieve an accuracy of $70 \%$ or greater in selecting an appropriate construction method. When considering that a random classification of three construction methods would generate an accuracy ratio of $1 / 3$, the deductions using these models achieved a comparatively high accuracy. The above results indicate that any of the above models can determine a construction method for use in construction planning based on data that expresses attributes of the construction project, provided all attributes are available.

However, the greatest problem in selecting a construction method using these evaluation models is the existence of predicting error in the models. As described above, none of the models have an accuracy of $100 \%$. In order to minimize the amount of error in these models, it must be known in advance whether the model produces a correct solution or not. The author used the majority principle in the present study, wherein a solution obtained from each model was compared to the solutions from other models in order 
